\title{
GLABROLIDE FROM THE ROOTS OF GIycyrrhiza aspera
}

\author{
N. P. Kir'yalov, V. F. Bogatkina,
}

UDC 547.913

and T. P. Nadezhina

The mixture of unpurified saponins isolated by the extraction of $150 \mathrm{~g}$ of the roots and rhizomes of Glycyrrhiza aspera Pall with water was hydrolyzed with $6 \% \mathrm{H}_{2} \mathrm{SO}_{4}$ in methanol (on the boiling water bath for $8 \mathrm{~h})$. The neutral hydrolysis products $(3 \mathrm{~g})$ were chromatographed on a column containing $120 \mathrm{~g}$ of $\mathrm{Al}_{2} \mathrm{O}_{3}$ (inactive), with elution by means of chloroform. The first fractions gave a substance of triterpene nature with $\mathrm{mp} 266^{\circ} \mathrm{C}$ having no absorption maxima in the UV spectrum; the IR spectrum showed a band at 1760 $\mathrm{cm}^{-1}$ (CO group of a $\gamma$-lactone).

The following product - methyl glycyrrhetate (yield $0.06 \%$ of the weight of the air-dry roots) - has been detected previously in the roots of this liquorice [1], and we identified it by its IR and UV spectra.

The main hydrolysis product $\left(0.25 \%\right.$ ), with the composition $\mathrm{C}_{30} \mathrm{H}_{44} \mathrm{O}_{4}$, which eluted simultaneously with the methyl glycyrrhetate, was recrystallized from ethanol, $\mathrm{mp} 360-365^{\circ} \mathrm{C},[\alpha]_{\mathrm{D}}^{20}+80^{\circ}$ (c 0.4; chloroform); UV spectrum: $\lambda_{\max } 243 \mathrm{~nm}$; IR spectrum, $\mathrm{cm}^{-1}: 3550(\mathrm{OH}), 1762$ (CO group of a $\gamma$-lactone), 1665 (CO group conjugated with a double bond), and 1628 (double bond). The compound isolated was identical in its chemical and spectral properties with glabrolide, which has been found in the roots of common liquorice [2]. For a more complete identification, its monoacetate was prepared: $\mathrm{C}_{32} \mathrm{H}_{46} \mathrm{O}_{5}, \mathrm{mp} 330-332^{\circ} \mathrm{C}$ (decomp.), $[\alpha]_{\mathrm{D}}^{20}+65^{\circ}$ (c 0.17 ; chloroform); UV spectrum: $\lambda \max 244 \mathrm{~nm}$; IR spectrum, $\mathrm{cm}^{-1}$ : 1782 (CO group of a $\gamma-$ lactone), 1740 (CO of an acetyl group), 1662 (CO group conjugated with a double bond), and 1625 (double bond). In addition, the hydrogenation of the glabrolide isolated formed deoxoglabrolide, $\mathrm{C}_{30} \mathrm{H}_{46} \mathrm{O}_{3}$ with mp $272-274^{\circ} \mathrm{C}$.

The subterranean organs of Gl. aspera were collected on June 5,1970 , in the flowering phase in the Kazakh SSR (near the village of Chelkar).

\section{LITERA TURE CITED}

1. N. K. Abubakirov and V. K. Yatsym, Uzb. Khim. Zh., No. 5, 80 (1959).

2. L. Canonica, G. Russo, and A. Bonati, Gazz. Chim. Ital., 96 (4), 772 (1966).

V. L. Komarov Botanical Institute, Academy of Sciences of the USSR. Translated from Khimiya Prirodnykh Soedinenii, No. 2, p. 277, March-April, 1973. Original article submitted November 2, 1972.

(C) 1975 Plenum Publishing Corporation, 227 West 17th Street, New York, N.Y. 10011. No part of this publication may be reproduced, stored in a retrieval system, or transmitted, in any form or by any means, electronic, mechanical, photocopying, microfilming, recording or otherwise, without written permission of the publisher. A copy of this article is available from the publisher for $\$ 15.00$. 